\title{
Announcement of the Fulker Award for a Paper Published in Behavior Genetics, Volume 42, 2012
}

Received: 8 August 2013/Accepted: 14 August 2013/Published online: 30 August 2013

(C) Springer Science+Business Media New York 2013

The Fulker Award was established by the Behavior Genetics Association in memory of David Fulker, a past President the Association and Executive Editor of the journal, who died in 1998 (Hewitt 1998). The award is for a particularly meritorious paper' published in the journal during the preceding year. The annual prize is $\$ 1,000$ 'and a nice bottle of wine' (given only when the recipient is present at the Association's annual meeting.)

Volume 42 included 75 rigorously peer reviewed papers on human and animal behavior genetics. To select the paper for the Fulker award, I solicit nominations from the journal's Associate Editors follow their advice closely.

Among the nominees were papers by: Bergin et al. (2012) on the genetic and environmental transmission of fluctuations in Body Mass Index, a health related phenotype; on methods for testing the hypothesis of an X-linked genetic influence resulting in the increased representation of males in the high end of the IQ distribution, by Giummo and Johnson (2012), by Kim et al. (2012) on sexual isolation in natural strains of Drosophila pseudoobscura that are possibly in the early stages of speciation; by Martin et al. (2012) on conspecific ant aggression and kin recognition; a study by Barclay et al. (2012) on the non-shared environmental influences on sleep quality; and a study of Orangutan personality, by Mark Adams and colleagues that was based on subjects from 42 zoos, connected through known pedigrees, across the USA, Canada, Australia and Singapore. One of the pleasures of being the Editor of Behavior Genetics is reading the wide range of innovative studies published in the journal, and making the almost impossible choice of the 'best' paper from among the Associate Editors' nominations.

This year, Adams et al. (2012) careful analysis of their fascinating and unique data stood out. Although not definitive, this paper is one of systematic and rigorous series of studies conducted by Alex Weiss and his students that provides an original and different approach to understanding the evolution of human personality through the study of non-human primates.

Congratulations to Mark Adams, James King, and Alex Weiss for their 2012 Fulker Award winning paper: The majority of genetic variation in Orangutan personality and subjective well-being is non-additive.

John K. Hewitt

Editor-in-Chief

\section{References}

Adams MJ, King JE, Weiss A (2012) The majority of genetic variation in orangutan personality and subjective well-being is nonadditive. Behav Genet 42:675-686

Barclay NL, Eley TC, Buysse DJ, Maughan B, Gregory AM (2012) Nonshared environmental influences on sleep quality: a study of monozygotic twin differences. Behav Genet 42:234-244

Bergin JE, Neale MC, Eaves LJ, Martin NG, Heath AC, Maes HH (2012) Genetic and environmental transmission of body mass index fluctuation. Behav Genet 42:867-874

Giummo J, Johnson W (2012) Testing for evidence of an X-linked genetic basis for a greater proportion of males with high cognitive ability. Behav Genet 42:808-819

Hewitt JK (1998) David William Fulker (1937-1998). Behav Genet 28:239-241

Kim YK, Ruiz-García M, Alvarez D, Phillips DR, Anderson WW (2012) Sexual isolation between North American and Bogota strains of Drosophila pseudoobscura. Behav Genet 42:472482

Martin SJ, Vitikainen E, Drijfhout FP, Jackson D (2012) Conspecific ant aggression is correlated with chemical distance, but not with genetic or spatial distance. Behav Genet 42:323-331 